\title{
Dual Applications for Metacognitive Development in Assisted Instruction
}

\author{
Gabriel ZAMFIR \\ Department of Economic Informatics and Cybernetics, \\ The Bucharest University of Economic Studies, Romania \\ zamfir@ase.ro
}

The improvements in technological infrastructures define the background of our e-society while the developments in the cognitive infrastructure explain the foreground of it. The background and the foreground of the e-science determine the growths of the e-business and the quality of the e-education. E-education evolves as an engine for the cognitive infrastructure of the $e$ society and it works with information technology, which is a dynamic concept in time and in space. This paper highlights the importance of the account between theory and practice in scientific research in e-education, reviewing the e-society timeline using an educational perspective. It describes an updated knowledge framework for scientific research in $e$ education, developing directions for comprehension of different analytical frameworks. Within a case study, it presents an approach based on classes of applications focused on metacognitive development in assisted instruction.

Keywords: Information Technology, Scientific Research in E-Education, Classes of Learning Applications in E-Society, Meta-Instruction in E-Education, Cognitive Development and Learning

1

\section{Introduction}

The evolution of our society depended on information from the very beginning. Different technologies developed in order to store, to retrieve, to transmit, or to process information described this evolution. However, in the November 1958 issue, Harvard Business Review published the article Management in the 1980's, by Harold J. Leavitt and Thomas L. Whisler. In that article, the authors had highlighted that "Over the last decade a new technology has begun to take hold in American business, one so new that its significance is still difficult to evaluate. While many aspects of this technology are uncertain, it seems clear that it will move into the managerial scene rapidly, with definite and far-reaching impact on managerial organization. The new technology does not yet have a single established name. We shall call it information technology." That article is available today online, at the web address: https://hbr.org/1958/11/management-in-the1980s. Nowadays, about information technology, Wikipedia, the free encyclopaedia, is warning us "Not to be confused with Informatics." Google search engine offers us autocomplete options for the keywords information technology as information technology definition, or information technology vs computer science or information technology and communications or information technology outsourcing. If the users edit the keywords information technology communication, others options available are networks, plan or definition, and if the search phrase is information technology communications, other options are manager job description, plan, or manager. Searching for Romanian keywords tehnologia informației, the autocomplete options are "si a comunicarii", "si a comunicatiilor", "referat". When we start a new search using the names Leavitt and Whisler, one Google's autocomplete option is "leavitt whisler 1958."

Using BizNar for searching "information technology," we get a search summary, a structured, or a visual result, and we can refine the search depending on topics, authors, publications, source, dates, document format or document type.

Using WolframAlpha for searching “information technology," we get a structured 
result assuming "information technology" is a general topic, or we can get different results using the phrase as an occupation or a word instead.

When Leavitt and Whisler named the new technology, they prognosticated that information technology should move the boundary between planning and performance upward, and much more of the work will be programed, i.e., covered by sets of operating rules governing the day-to-day decisions that are made. At the same time, the authors considered that a radical reorganization of middle-management levels should occur, with certain classes of middle-management jobs moving downward in status and compensation (because they will require less autonomy and skill), while other classes move upward into the top-management group [1]. The same authors highlight the idea that on a broader social scale one can conceive of large problems outside the firm that affect many institutions ancillary to industry. In this context, they ask how we educate people for routinized middle-management jobs, especially if the path from those jobs up to top management gets much rockier, and to what extent do schools start training new kinds of specialists?

In 1964, [2] emphasized that in operational and practical fact, the medium (defined as any extension of ourselves) is the message. The author explained that the personal and social consequences of any medium result from the new scale that is included into our affairs by each extension of ourselves, or by any new technology. In addition, he gives two examples: the restructuring of human work and association which were shaped by the technique of fragmentation, which it was the essence of machine technology, while the essence of automation technology is the opposite, it is integral and decentralist in its patterning of human relationships.

"In 1969, Nippon Calculating Machine Corporation approached Intel to design 12 custom chips for its new Busicom 141-PF* printing calculator. Intel engineers suggested a family of just four chips, including one that could be programmed for use in a variety of products, setting in motion an engineering feat that dramatically altered the course of electronics. In 1971, Intel® 4004 became the first general-purpose programmable processor on the market - a "building block" that engineers could purchase and then customize with software to perform different functions in a wide variety of electronic devices." That was the idea of including a computer inside a computer: http://www.intel.com/content/www/us/en/his tory/museum-story-of-intel-4004.html.

Connected computers in networks and then, connected contents within separate documents, as we may think, represented the groundwork in order to design a new learning environment for e-education.

In 1987, [3] mentioned that "today, more than ever before people involved both directly and indirectly with the educational enterprise are caught up in efforts to introduce and integrate computers into the curricula of the nation's schools. The concept involved, that of using computers for instruction, is referred to as novel, innovative, and new, but what is not generally known is that instructional computing has been around for quite a while". In 1991, [4] included in the printed book the article [5], which underlined that affluent districts use computers to empower children to soar upward in the range of intellectual capabilities. Poor schools characteristically employ computers for repetitive and rote activities - a passive and unimaginative use that duplicates the function of old-fashioned workbooks.

Concentrating on the adoption and implementation of educational technology in 1994, [6] outlined and compared the conceptual definitions of educational technology (ET) and information systems (IS). ET and IS definitions focusing on devices, people, knowledge, and processes suggest a theoretical linkage between ET and IS application and adoption. The author reflects the educational changes citing [7], which it identifies four distinct phases: adoption (1960s), implementation failure (1970-1977), implementation success (1978-1982), and intensification versus restructuring (1983- 
1990). Referring to information systems adoption, [6] mentions that there have been three generally recognized eras. In the first period, from 1954 to about 1964, the computers represented hardware support for accounting and office applications in major organizations. In the second period, from around 1965-1980, the breadth of applications expanded due to improve general-purpose programming language. The third period, it began with the advent of microcomputers, around 1980. The author concludes that one important factor for ET adoption that should be assumed from the IS factor model, it is that of involving users directly in the design process.

In 2008, referring to [8], the author considered that educators are increasingly using educational technologies at the postsecondary level although little research has investigated the effects of such technologies on learning. This study explored the effects of traditional lecture, slideshow-supplemented lecture, and virtual learning environment (VLE) on learning and frustration among college students. The results are that participants in slide-show-supplemented lecture and VLE conditions demonstrated more learning than participants in the traditional lecture conditions. However, participants in the VLE conditions reported significantly higher levels of frustration relative to those in the traditional lecture and slide-showsupplemented conditions. The same author considers that his findings may be particularly relevant in light of the increasing numbers of online college degree programs that use VLE platforms.

In 2016, The New Media Consortium published a report [9], based on the collaborative research and discussions of a body of 58 experts, which it charts the fiveyear horizon for the impact of emerging technologies in colleges and universities across the globe. This report highlights three directions:

a) Key trends accelerating technology adoption in higher education:

- Short term: growing focus on measuring learning and increasing use of blended learning design;

- Mid-term: redesigning learning spaces and shift to deeper learning approaches;

- Long term: advancing cultures of innovation and rethinking how institutions work.

b) Significant challenges impeding technology adoption in higher education:

- Solvable challenges: Those that we understand and know how to solve: blending formal and informal learning and improving digital literacy;

- Difficult challenges: those that we understand but for which solutions are elusive: competing models of education and personalizing learning;

- Wicked challenges: those that are complex to even define, much less address: balancing our connected and unconnected lives and keeping education relevant.

c) Important developments in educational technology for higher education:

- Time to adoption horizon: one year or less: Bring Your Own Device and Learning Analytics and Adaptive Learning;

- Time to adoption horizon: two or three years: Augmented and Virtual Reality, and Makerspaces;

- Time to adoption horizon: four or five years: Affective Computing and Robotics.

At the same time, in [10], the author mention that in this $21^{\text {st }}$ century, children are increasingly exposed to electronic media at a young age, often with the expectation that this provides them with better learning opportunities. Alphabet eBooks are inexpensive and readily downloadable from the internet and are marketed as learning tools. When children use alphabet eBooks, adult guidance to shift their focus to the letters, elicit imitation of sounds and names, and encourage naming of the letters and pictures would enhance the learning opportunities provided by this medium.

From the point of view of e-education, this timeline of the e-society reveals the main 
features of our society, globalization, diversity, and dynamism. In order to understand this perspective, the conceptual framework of [11] exposes three kinds of infrastructures, which are likely to emerge: technological infrastructure, conceptual infrastructure and the cognitive infrastructure. Globalization is a result of the technological infrastructure, while diversity is a concept developed by the cognitive infrastructure.

Using a search engine, a meta-search engine, or a semantic one, for the phrase "e-society timeline," we study a generic concept, in a theoretical approach, while looking for the phrases "technological infrastructure," "conceptual infrastructure," or "cognitive infrastructure," for a particular type of organization, we study an entity, in a practical approach. Such an understanding concludes the necessity of a dynamic development of the scientific research in e-education in order to optimize the conceptual infrastructure, based on a continuous progress of the knowledge framework, which means rationalized comprehension framework, reorganized application framework, and updated study cases.

\section{Knowledge Framework}

Based on the theoretical framework presented in [12], and correlated with the methodological approach developed in [13], it is necessary to highlight that the concept "scientific research" implies, by default, an "information technology" version. At the same time, theoretical structuring of the content is a continuous recursive process, while practical implementations are iterative processes. The paradigm between metalanguage and object language used to develop learning processes, based on knowledge, comprehension, and application depends on the e-education programs particularized for this purpose. In this context, the result of a reviewed knowledge framework of the scientific research in e-education is presented in the in the image of the Fig. 1.

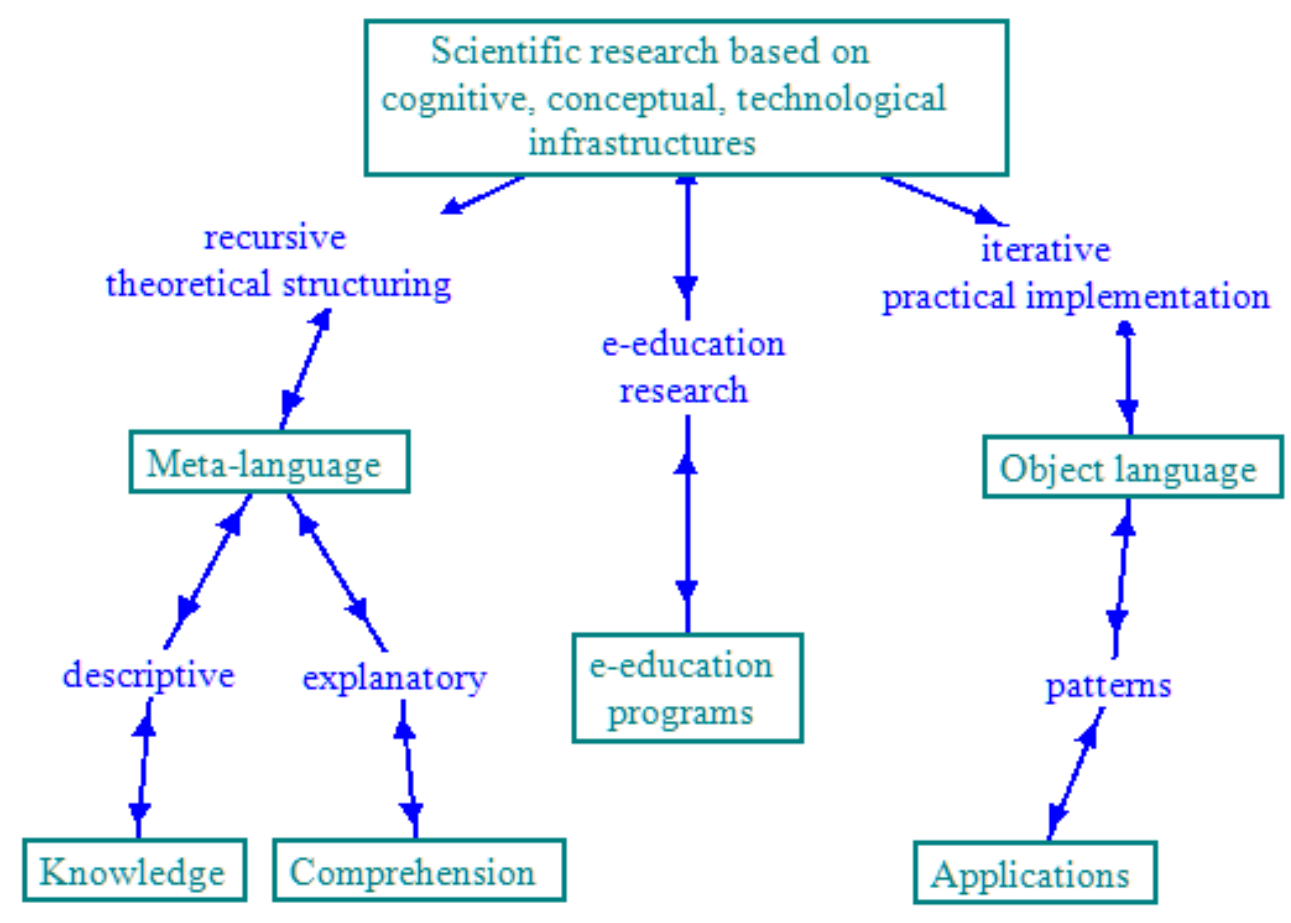

Fig. 1. A knowledge framework for the scientific research in e-education

A knowledge framework consists of keywords as basic concepts of a scientific research area, characterized by specific functionalities, which enable them integration in a comprehension framework. The comprehension framework consists of keywords as aggregate concepts, which enable them advancing in an application 
framework. The application framework consists of keywords as threshold concepts which enable them validating in case studies. Therefore, we develop an integrated methodological based on concepts map approach. Meta-language describes or explains theoretical content, while object language integrates patterns of a technology implementation as applications. Such an approach describe e-society as an educational laboratory. It is useful to know that this concept was present in professional works in 1966, in [14], as regional educational laboratories. The regional educational laboratories were programs developed to meet the particular needs of each region. The author presented, as example, the Appalachia Lab, which it had as its objectives: (a) to reduce cultural deprivation, (b) to modernize the curriculum, (c) to combat isolation, (d) to improve the transition from school to work, (e) to raise educational aspirations, and (f) to speed educational change.

In 2017, involved in a theoretical approach concerning personalized e-Learning framework, [15] mentions: "The World Wide Web (WWW) has a huge amount of documents and lots of information, only accessible by human users. Knowledge in the Internet is notorious for its vastness, semantically duplicated terms, vagueness, incompleteness, uncertainty, and inconsistency." Referring to the concept "technology," the same author specifies, "Current technology has the potential to construct an e-learning environment that is capable of acquiring preferences of learners, building and managing sharable and reusable semantically modelled learning entities, and providing customized e-learning services for each individual learner according to his/her preferences and personal characteristics. These technologies are: learning objects, ontology, semantic web, and content management systems."

Another author, [16] highlights that "The rapid global changes in information and communication technology, has affected the availability of technology and made it pervasive. The permeation of technology in society has forced changes in employment and education. The new skills needed for navigating education and the workplace in the current century have been labelled $21 \mathrm{st}$ century skills and are characterized as being critical for functioning effectively in society". That explains a number of national and international frameworks, which have been outlined to systematize and define $21 \mathrm{st}$ century skills.

Analysing e-society as an educational laboratory from the point of view of the cognitive development of the e-citizen, correlated with learning as a specific human activity, we have to observe a dynamic terminology, consisting of acronyms, abbreviations, or keywords in fixed phrases. This dynamic terminology denotes concepts reflecting a very high level of generality, and it refers theories, ontologies, methodologies, methods, or different versions of implemented applications, which require a specific discipline in order to teach or to learn it. Such an approach explains the knowledge framework as a conceptual one.

\section{Comprehension Framework}

Understanding e-society as an educational laboratory, it presumes that e-education includes the classical form, and it is developing as an extension of the previous one [11]. E-Society represents an application of e-Science in social services, and it is going to reveal a learning system for each application of the information technology involved [17]. Referring to the information technology, we understand the cognitive infrastructure, the conceptual infrastructure, both of them, based on technological infrastructure. In the same reference, in the application framework, e-society defined as a society of the systems, includes the main learning systems in e-education, which depend on time and space. Learning systems in e-education involves standard eClassrooms, which integrate assisted instruction, consisting of computer-assisted instruction and teacher assisted learning, and which presume principles. The basis of any software application or service of an e- 
education system are the principles [18]. In e-education, individualized educational activities represents the first principle, and this is the first characteristic of a standard eClassroom. The second principle descends from the first one; personalized learning integrates the student-own-pace concept. Cognitive interactivity defines the functionalities of a learning system in eeducation. Based on the triple-vision of the personal computer as tool, tutor, and tutee, the third principle depends on the adequate information granularity of the digital content. This fourth principle of the e-education develops in a concept map approach. Using technology develops as a meta-discipline, while it integrates interdisciplinary approaches because of the diversity as forms of knowing and transdisciplinary approaches because of the diversity as forms of knowledge.

Referring information technology as the triad of the infrastructures: cognitive, conceptual, and technological, we define e-Science as scientific research activities based on information technology. The interrelationship of the building blocks of scientific research in e-society include methodology as an explicit version of the integrated information technology, and the methods become learning designed applications for each level of the content, see the image in Fig. 2.

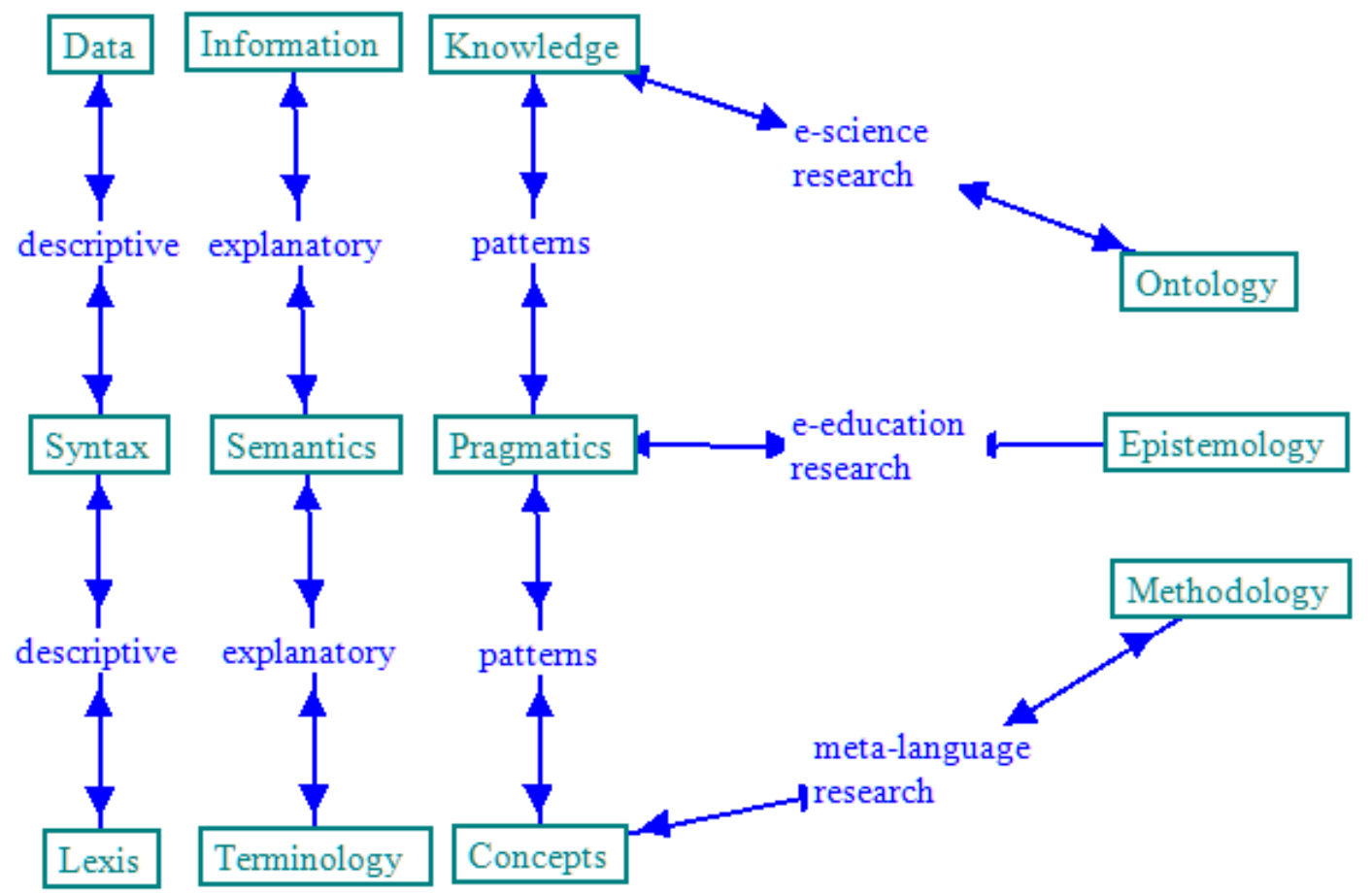

Fig. 2. Classes of learning applications in e-society

Including meta-language research as a main direction of the scientific research in e-society has a twofold explanations. First, English is a native language for the technological infrastructure domain. Second, as [19] mentions, "The privileged role of English as a data source in theorising pragmatics has been somewhat ameliorated in recent years as an increasing number of studies of pragmatic phenomena in a wide range of languages and cultures, including those of East Asia, have been undertaken. The role English plays, as a scientific metalanguage, in contrast, has remained largely unquestioned. Yet, as a number of researchers have pointed out, the language in which the description, analysis and theorisation of pragmatic phenomena is undertaken can influence how the research object(s) in question are understood". The same author highlights that "The essential problem is that words, although they may be analogous in many ways, rarely, if ever, have exactly the same meaning across languages, or even different varieties of that language, 
and they can be used to conceptualise our physical, mental, and social worlds in quite different ways".

Standard assisted instruction applications in eeducation represent a learning environment developed as tool, tutor, and tutee in the same session, which is guiding the student to finalize a script in order to solve a problem. Practically, he has to get a solution, but theoretically, he has to understand a method. Finalizing the application, the student should be capable to describe the method, as a cognitive development and he could explain it, as a metacognitive development. In order to demonstrate the cognitive development, the student needs a lexical base, advanced as a terminological one, specific to the studied domain, while the metacognitive development could be proved using a lexical base, advanced as a conceptual one, as soon as his activities transferred the knowledge as a pattern of the application environment.

This approach reflects the idea presented in [20]: "All learning takes place within an orderly pattern of development. At any time, learning is constrained by the developmental level of the learner." The same author highlights the key concept of Vygotsky's theory, the zone of proximal development and his instructional application referring the use of a technique called scaffolding.

\section{Application Framework}

Defining learning as a triad of stages, consisting of knowledge, comprehension, and application, the triple-vision of a standard assisted instruction application as tool, tutor, and tutee, enables personal computer as an eeducation environment. Reading the steps of the activities, reading how to do these actions, doing these actions and checking the correctitude of every each step, or reading how to correct and correcting the wrong actions, all of these movements reflect cognitive development as a learning process. Confirming learning, understood as a metacognitive development, it is possible, in a theoretical approach, describing the method, or, in a practical approach, using a dual application of the same class of problems, as it is presented in the image in Fig. 3.

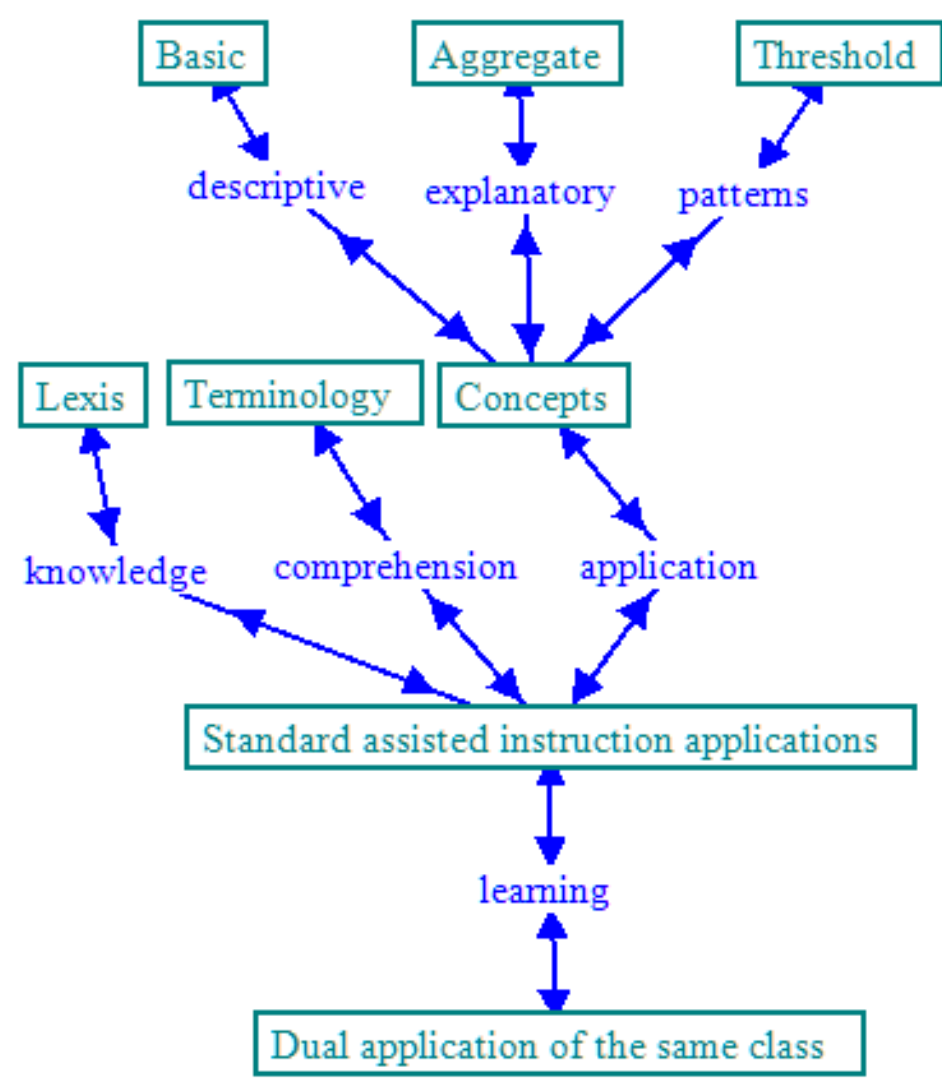

Fig. 3. Learning environment in e-education 
A standard assisted instruction application creates a learning environment, but the student, as a generic user, with unknown prerequisite in the field, has four directions for concentrating. Three of these are observable: the tool (what to do), the tutor (how to do), and the tutee (it was well done, or not), but the last one, and the most important, it is hidden. The fourth direction is the method applied in order to solve the initial statement. This is the cognitive development because of a learning process. Finally, we can ask the student if he had understand the method, we can ask the student to present the steps of the method, or we can ask the student to solve a new application of the same class. Developing the dual application, we transform the hidden functionality of a standard assisted instruction application in a revealed one, and so, we convert the theoretical concept of learning in a practical one, based on cognitive development, completed by the corresponding metacognitive development.

\section{Case Study}

Referring to intelligence, [21] define the concept as being "the ability to respond adaptively to new situations, to think abstractly and to comprehend complex ideas." In e-education, we find this definition referring to learning, and we could revise the definition of intelligence as the competence of transforming theory into practice. This is the reason we integrate the intelligence tests in standard assisted instruction applications and sustain cognitive development as a learning activity. In this case, we mix the exercise 14, from Test one of the same author; see the image in Fig. 4.

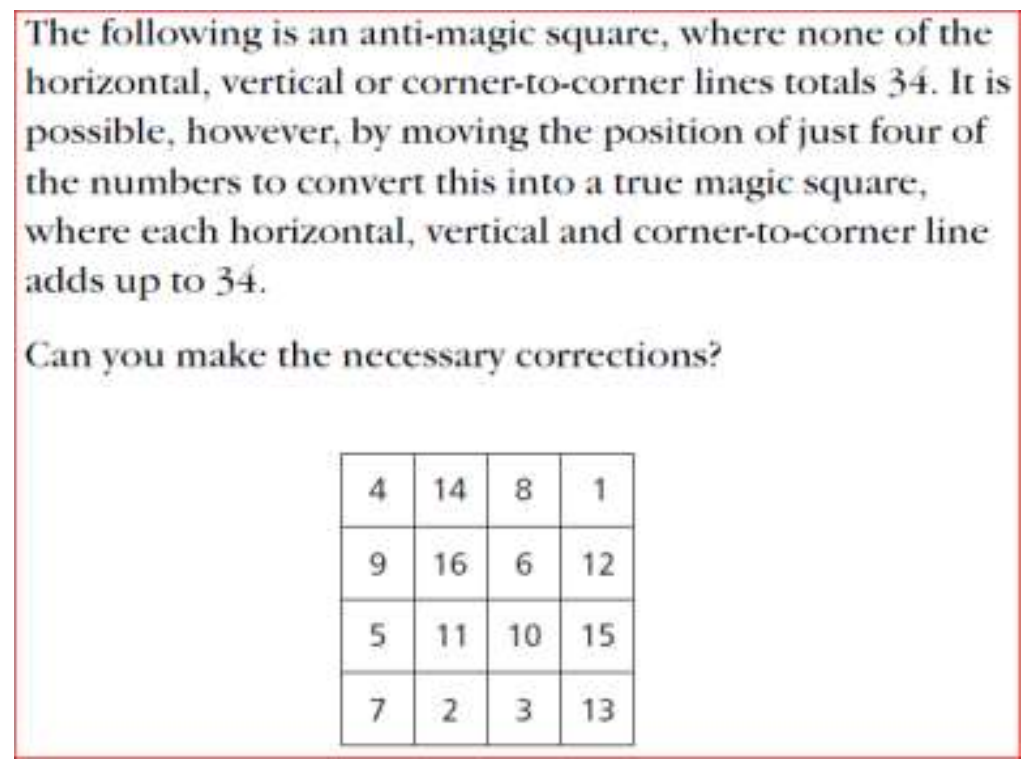

Fig. 4. The initial statement of the exercise

In order to solve this exercise, we present the newest version of a standard assisted instruction application, created initially as an interdisciplinary approach for interactive evaluation, described in [11], which offers to the student a method for comprehension, based on a spreadsheet. The interface of the application contains the main functionalities: tool, tutor, and tutee, see in the image in Fig. 5. 


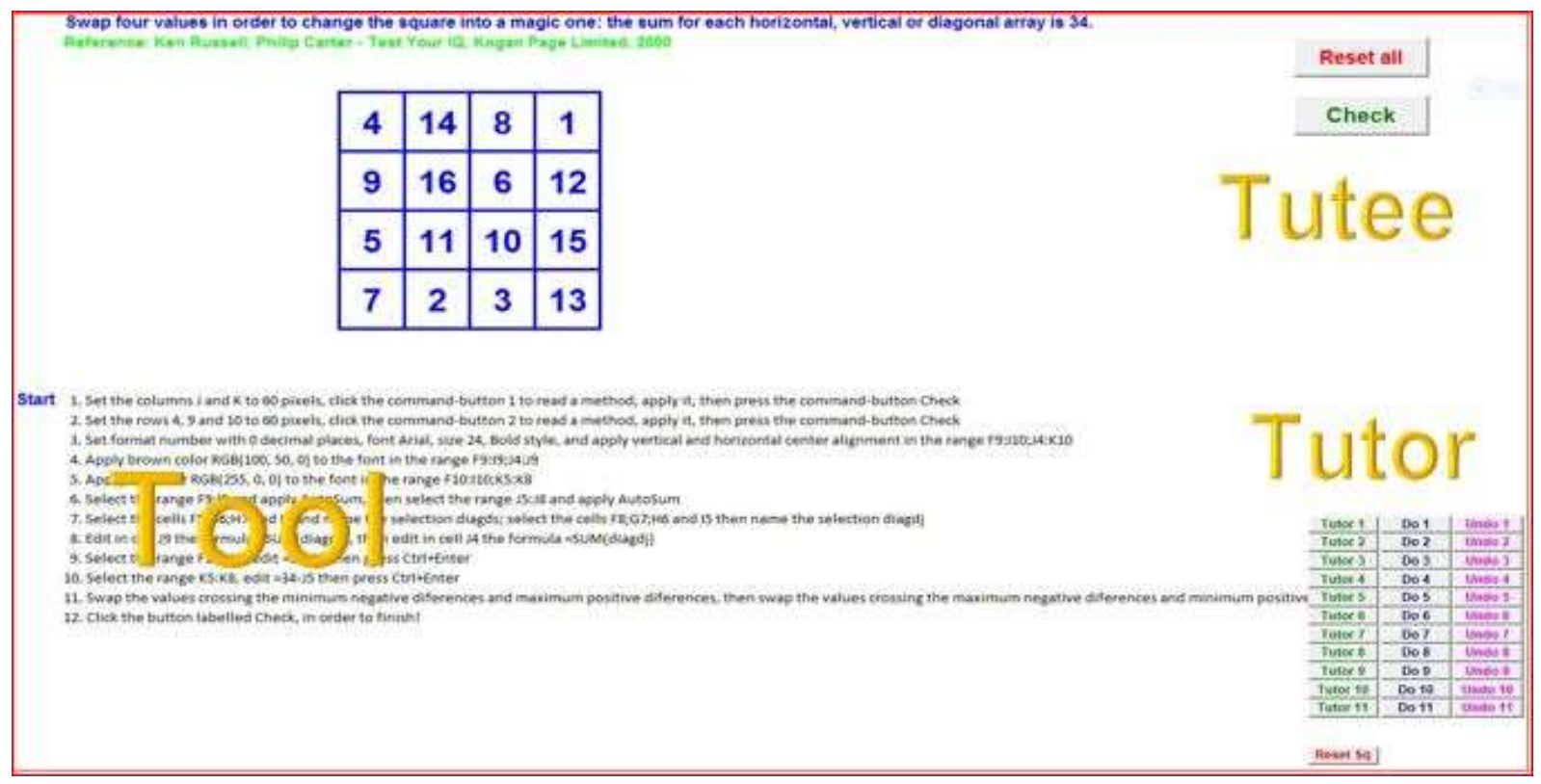

Fig. 5. The interface of the standard assisted instruction application

The statement of the application is visible on the first row: Swap four values in order to change the square into a magic one: the sum for each horizontal, vertical, or diagonal array is 34. The second row contains the reference.

As a tool, the domain situated under the square contains the activities the student has to proceed.

The activities, structured in 12 steps, are the following:

1. Set the columns $\mathrm{J}$ and $\mathrm{K}$ to 60 pixels, click the command-button Tutor 1 to read a method, apply it, then press the commandbutton Check.

2. Set the rows 4,9 and 10 to 60 pixels, click the command-button Tutor 2 to read a method, apply it, then press the commandbutton Check.

3. Set format number with 0 decimal places, font Arial, size 24, Bold style, and apply vertical and horizontal centre alignment in the range $\mathrm{F} 9: \mathrm{I} 10 ; \mathrm{J} 4: \mathrm{K} 10$

4. Apply brown colour, $\operatorname{RGB}(100,50,0)$ to the font in the range F9:I9;J4:J9

5. Apply red colour $\operatorname{RGB}(255,0,0)$ to the font in the range $\mathrm{F} 10: \mathrm{I} 10 ; \mathrm{K} 5: \mathrm{K} 8$

6. Select the range F9:I9 and apply
AutoSum, then select the range J5:J8 and apply AutoSum

7. Select the cells F5;G6;H7 and I8 and name the selection diagds; select the cells F8;G7;H6 and I5 then name the selection diagdj

8. Edit in cell $\mathrm{J} 9$ the formula $=\mathrm{SUM}($ diagds $)$, then edit in cell $\mathrm{J} 4$ the formula $=\mathrm{SUM}($ diagdj $)$

9. Select the range F10:I10, edit $=34-F 9$ then press Ctrl+Enter

10. Select the range $\mathrm{K} 5: \mathrm{K} 8$, edit $=34-\mathrm{J} 5$ then press Ctrl+Enter

11. Swap the values crossing the minimum negative differences and maximum positive differences, and then swap the values crossing the maximum negative differences and minimum positive differences

12. Click the command-button labelled Check, in order to finish!

Therefore, each step has assigned a commandbutton as a tutor, labelled with the number of the step, which reveal a method to execute the statement. As soon as the seventh step is a level two difficulty because it includes hidden attributes of a range, when the operation fails, the same tutor button associated with that operation will reveal the necessary action to correct, if it has happened! See the image in Fig. 6. 


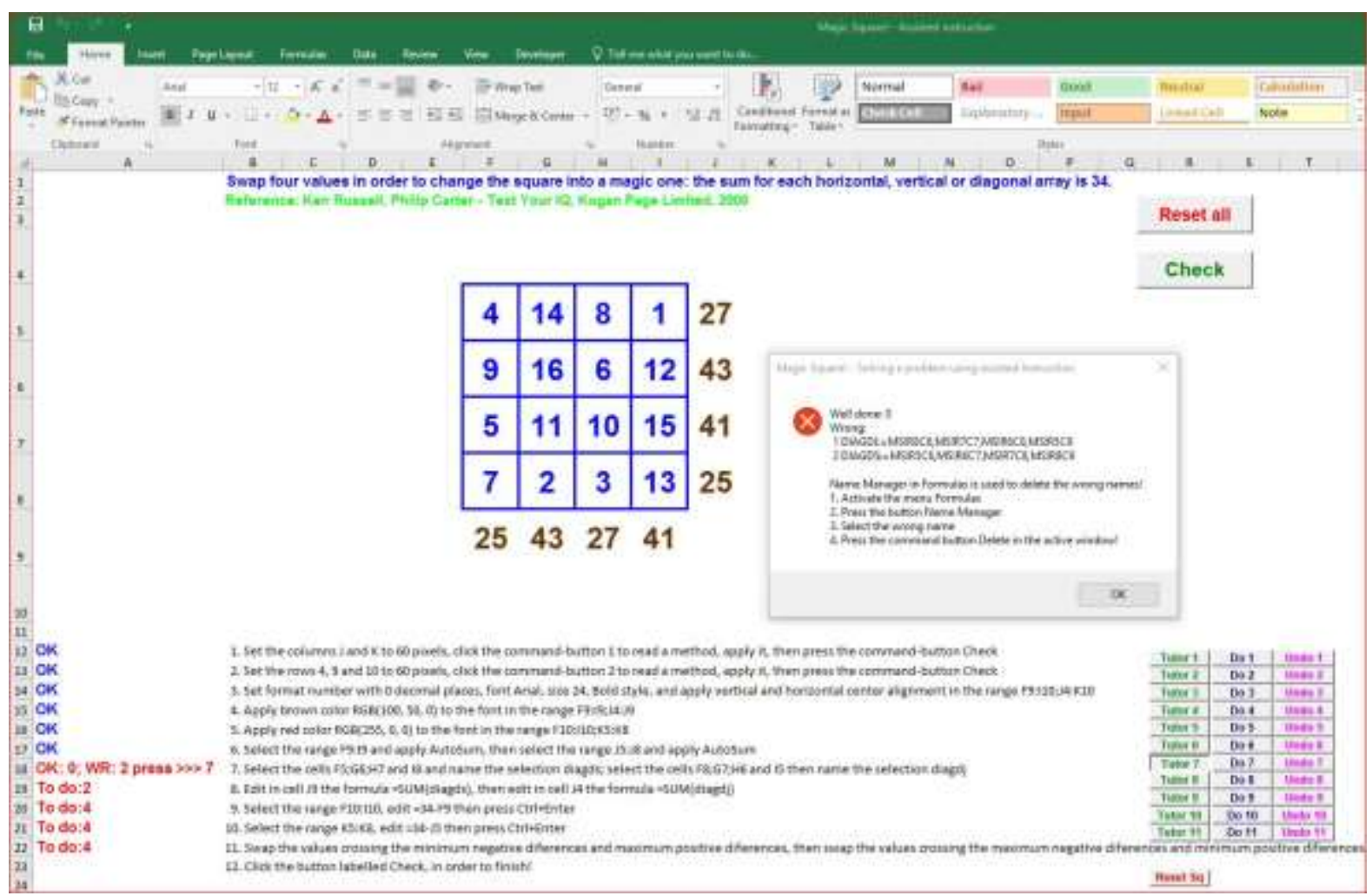

Fig. 6. Necessary action to correct, when the operation fails

There are also, two command-buttons: Reset all and Reset Sq, to repair the entire context or only the square domain, if it is necessary. In order to encourage the student to explore before action, there are a couple of commandbuttons for each step, labelled Do and Undo, which implement a system action for solving and user observing, then resetting the action, to permit the user action.

The command-button labelled Tutor 11 will review the method of the initial statement, in order to help the user to recognise it.

The application integrates external concepts of the learning environment, such as system drive, path, folder, computer name, user name, and, at the same time, it is monitoring the student activities, tracking the uses of the tutor command-buttons, uses of the commandbuttons Check, Reset all, or Reset Sq, and the period necessary to solve the exercise. The final screen is in the image in Fig. 7.

As soon as confirming learning by the students means a theoretical answer regarding the steps of the method, associated with the files of the application, in order to solve the exercise that was a theoretical confirmation, and not an assisted instruction solution. 


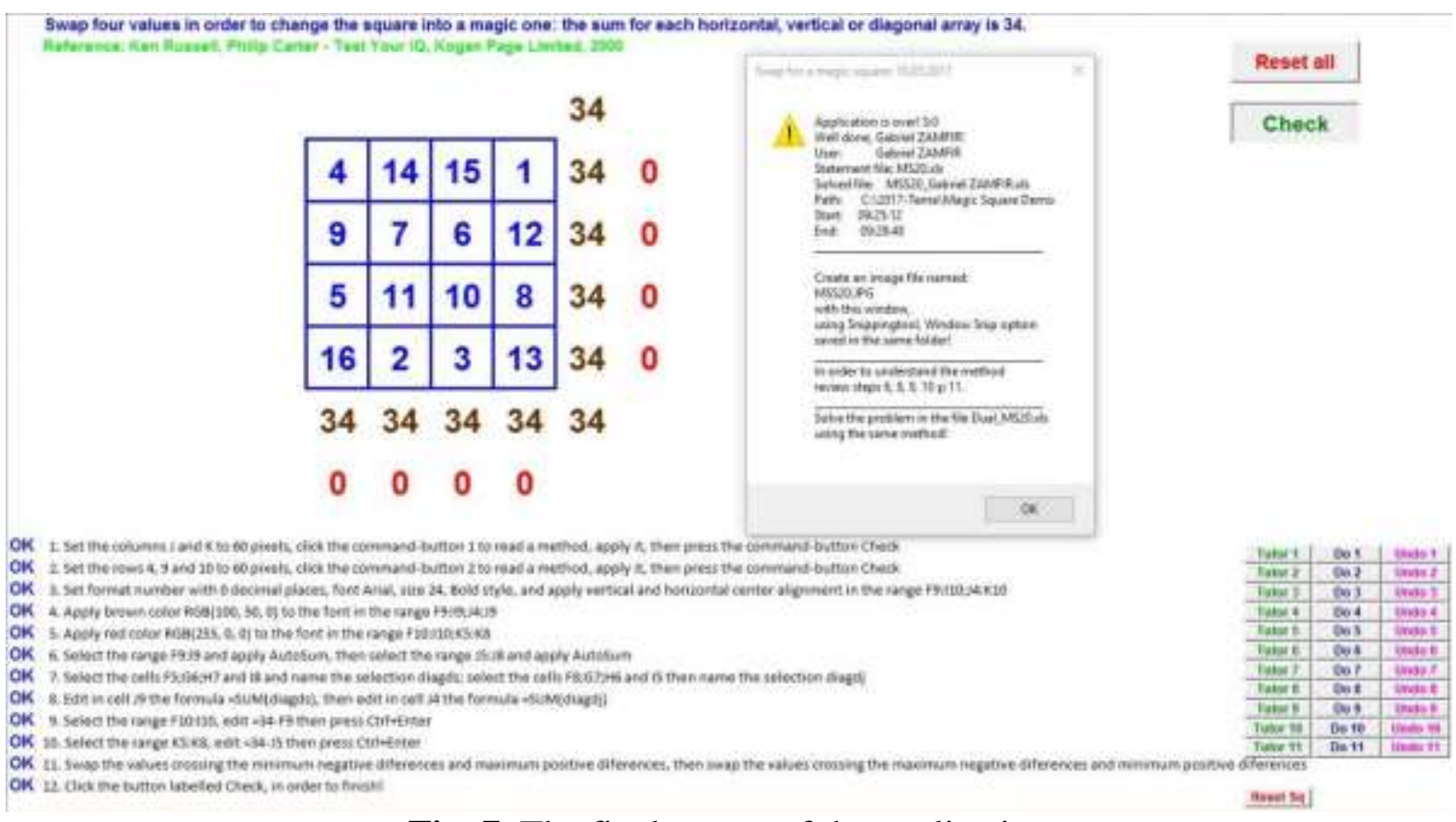

Fig. 7. The final screen of the application

This is the reason of the next stage of an application framework based on the dual applications of the same class, when the students confirm learning solving a new application, based on the same method; the new application was generated when the first exercise was completed.
A new and potential exercise for the dual application could be seen in imagine in Fig. 8, but this one has the same solution as the first exercise, so the student could apply the solution and not the method supposed to be learned.

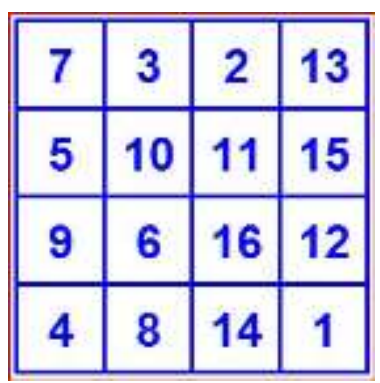

Fig. 8. A new exercise of the same class, ineligible for this approach

Selecting an eligible exercise, the interface of the dual application, generated at the end of the first application, after the final confirmation, presented in Fig. 7, contains the initial statement of the same class of problems and the new square, so the student only has to apply the method learned, see the image in Fig. 9. 


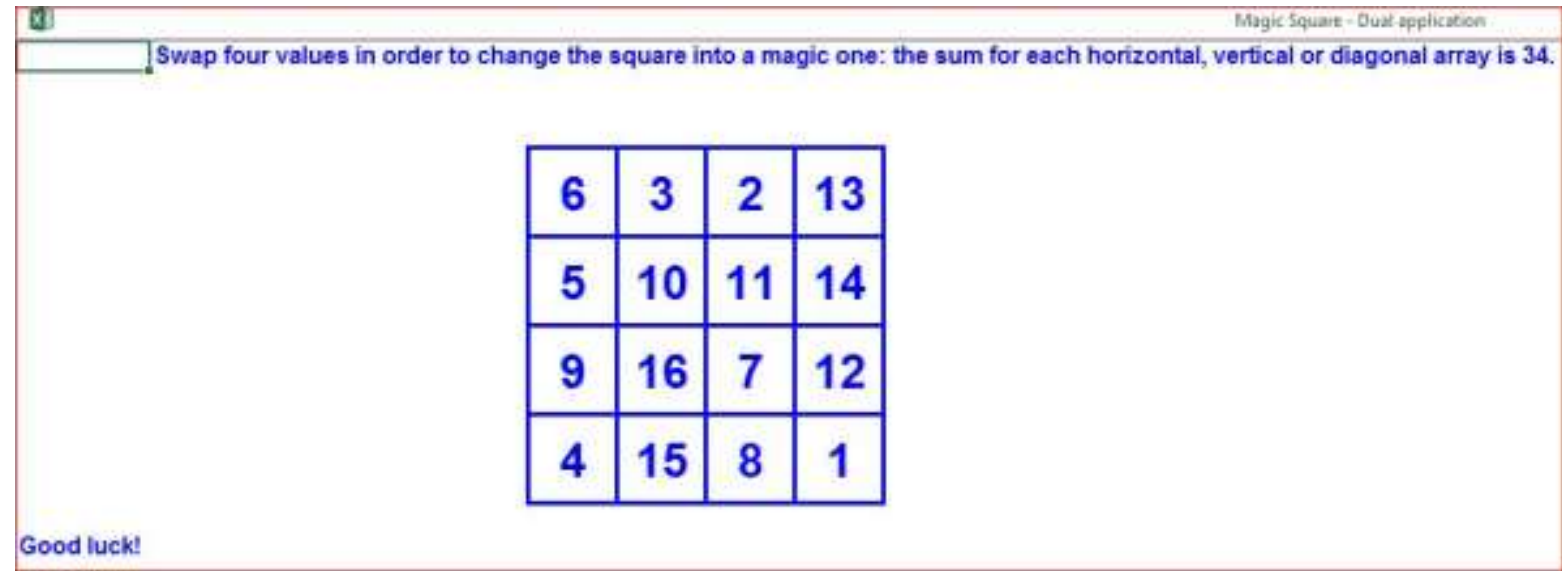

Fig. 9. Dual application for the same method

The student confirms learning, understood as a metacognitive development, in a theoretical style, describing the method, and, in a practical manner, finalizing a dual application of the same class of problems.

This approach, developed as a new paradigm of meta-instruction in e-education, could also provide the student opportunities to develop and refine his transversal competencies, recommending two Google images searches, using the two images presented in Fig. 10. First image, placed on the left side, is an Albrecht Dürer's work created in 1514, the second one is the magic square obtained in the dual application, extracted from Dürer's engraving.

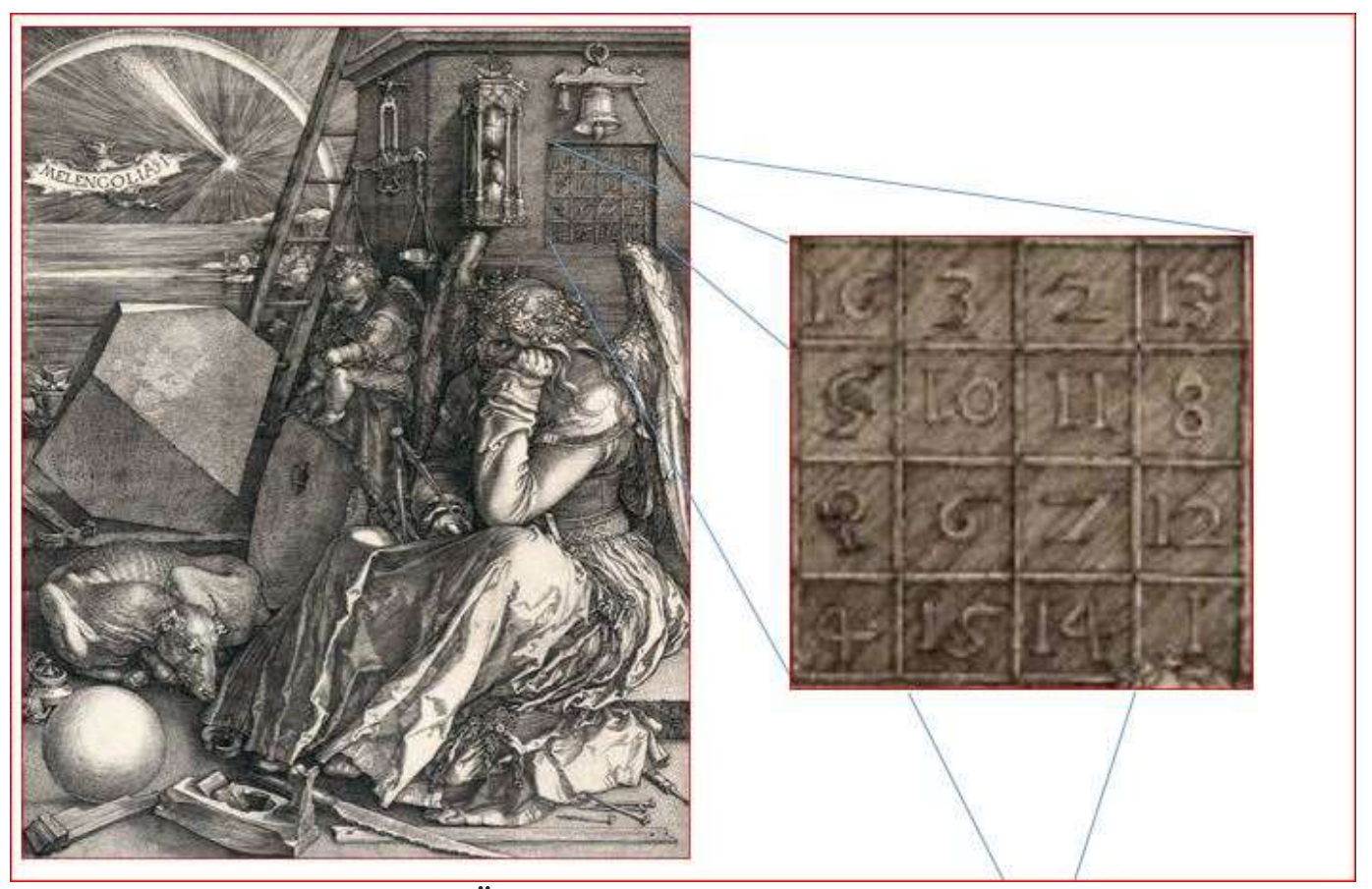

Fig. 10. A. DÜRER's engraving Melancholia (1514)

\section{Conclusions}

Information technology was born as a dynamic concept in time and in space, preparing Gordon Moore's prediction, and today it reflects a too general approach in eeducation. The threefold infrastructure, highlighted in this article, as technological, cognitive, and conceptual instances, remains a theoretical and wide-ranging approach with different influences in education for learning process, and in e-education for teaching activities. These influences explain delaying of standard solutions for implementations, but the stake is a major one: the cognitive 
development of the user could remain behind the dynamics of the technological infrastructure or the technological infrastructure could become a cognitive extension of the user. The difference between the two possibilities consists of treating learning as a theoretical concept or as a practical one.

\section{References}

[1] H. J. Leavitt, L. T. Whisler, "Management in the 1980's," Harvard Business Review, November-December 1958, [Online]: Available at: https://hbr.org/1958/11/management-inthe-1980s

[2] M. McLuhan, Understanding Media, The Extension of Man, McGraw-Hill, 1964, ISBN: 81-14-67535-7, 318p.

[3] R. V. Bullough, Sr., L. F. Beatty, Classroom applications of microcomputers, Merrill Publishing Company, Columbus, Ohio 1987, Library of Congress Catalog Card Number: 8661507, International Standard Book Number: 0-675-220525-5, 342 p.

[4] L. J. Echternacht (ed.), Introduction to Microcomputer in Education, Kendall/Hunt Publishing Company, Dubuque, Iowa, 1991, ISBN: 0-84037067-9, $244 \mathrm{p}$.

[5] J. Kozol, Rich Child, "Poor Child," Electronic Elearning, Special Edition, February 1991

[6] S. L. Schneberger, K. L. Jost, "Educational Technology Adoption: An Information Systems Perspective," in Proc. of Selected Research and Development Presentations at the 1994 National Convention of the Association for Educational Communications and Technology, $16^{\text {th }}$, Nashville, TN, February 16-20, 1994

[7] M. Fullan, The New Meaning of Education Change, New York, Teachers College Press, 1991

[8] M. C. Hove, K. J. Corcoran, "Educational Technologies: Impact on Learning and Frustration," Teaching of Psychology, 35: 121-125, 2008, DOI: $10.1080 / 00986280802004578$
[9] L., Johnson, S., Adams Becker, M., Cummins, V., Estrada, A., Freeman, and C. Hall, NMC Horizon Report: 2016, Higher Education Edition, Austin, Texas: The New Media Consortium

[10] M. A. Evans, S. Nowak, B. Burek, D. Willoughby, "The effect of alphabet eBooks and paper books on pre-schoolers' behavior: An analysis over repeated readings," Early Childhood Research Quarterly, 40, 0885-2006/2017 Elsevier Inc.

[11] G. Zamfir, "Learning e-Learning," Informatica Economica, Volume 13, No. 4/2009, pp. 51-62

[12] G. Zamfir, "Didactics in Assisted Instruction," in Proc. of HumanComputer Interaction National Conference, ROCHI 2010, pp. 59-64, available at: http://rochi.utcluj.ro/rrioc/articole/RoCHI -2010/RoCHI-2010-Zamfir.pdf

[13] G. Zamfir, "Learning Paradigms in eSociety," Informatica Economica, Volume 17, no. 3, 2013, pp. 99-113, DOI: 10.12948/issn14531305/17.3.2013.09,

[14] R. S. Gilchrist, F. W. Markus, "The Regional Educational Laboratory: Implication for the Future," Association for Supervision and Curriculum Development, available at http://www.ascd.org/ASCD/pdf/journals/ ed_lead/el_196610 gilchrist.pdf

[15] M. M. Alhawiti, Y. Abdelhamid, "A Personalized e-Learning Framework," Journal of Education and e-Learning Research, Vol. 4, No. 1, 15-21, 2017, http://asianonlinejournals.com/index.php/ JEELR

[16] F. Siddiq, P. Gochyyev, M. Wilson, "Learning in Digital Networks e ICT literacy: A novel assessment of students' 21st century skills," Computers \& Education, 0360-1315/ 2017 Elsevier Ltd., http://www.sciencedirect.com/science/arti cle/pii/S0360131517300210

[17] G. Zamfir, "Assisted Learning Systems in e-Education," Informatica Economica, Volume 18, no. 3, 2014, pp. 91-102, DOI: 10.12948/issn14531305/18.3.2014.08 
[18] G. Zamfir, "Learning Support for Standard e-Classroom," Informatica Economica, Volume 19, no. 3/2015, DOI: 10.12948/issn14531305/19.3.2015.04, pp. 46-58

[19] M. Haugh, "The role of English as a scientific metalanguage for research in pragmatics: Reflections on the metapragmatics of "politeness'," East Asian Pragmatics, Vol. 1.1 2016, 39-71, 2016, EQUINOX PUBLISHING doi: 10.1558/eap.v1i1.27610, https://journals.equinoxpub.com/index.ph p/EAP/article/view/27610/pdf

[20] J. N. Hopper, J. A. Carter-Wells, The
Language of Learning, Third Edition, Heinle, a division of Thomson Learning, Inc.

[21] P. Carter \& K. Russell, Test Your IQ, 400 questions to boost your brainpower, Kogan Page Limited, First published in 2000, Reprinted in 2001, 2004, Reissued in 2007, London

[22] *** - Albrecht Dürer Master Drawings, Watercolors, and Prints from the Albertina, Board of Trustees, National Gallery of Art, Washington, March 24 - June 9, 2013, http://www.nga.gov/content/ngaweb/exhi bitions/2013/durer_albertina.html

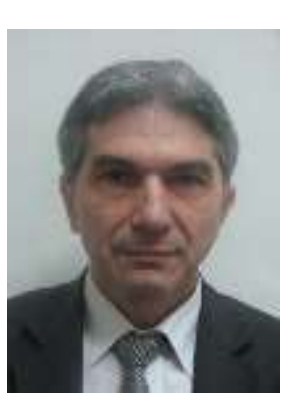

Gabriel ZAMFIR has graduated the Faculty of Planning and Economic Cybernetics from the Academy of Economic Studies Bucharest, in 1984. He worked as analyst for six years and as a researcher for three years at the Research Institute for Computers. In 1993, he joined the staff of the Bucharest University of Economics. In 2000, he finalized the doctoral thesis Computer Assisted Instruction in Economics. Currently he is professor at the Department of Economic Informatics and Cybernetics, interested in research and applications design for e-education. 